\title{
Multi-Day Low Dose Ketamine Infusion for the Treatment of Complex Regional Pain Syndrome
}

Michael E. Goldberg, MD, Richard Domsky, MD, Denise Scaringe, MD, Robert Hirsh, MD, Jessie Dotson, MSN, Imran Sharaf, MD, Marc C. Torjman, PhD, and Robert J. Schwartzman, MD

Background: Complex regional pain syndrome (CRPS) is characterized by pain that is out of proportion to the injury and is regional in distribution. A large body of literature supports a dynamic change in the physiology and structure of central pain projecting neurons mediated through the $\mathrm{N}$-methyl-Daspartate (NMDA) receptor. A critical factor in central sensitization seems to be the release of the magnesium block on the NMDA receptor with influx of calcium and initiation of intracellular cascades. Current literature supports the effectiveness of ketamine in blocking central sensitization through its effects on the NMDA receptor. Recent treatment with anesthetic doses of ketamine in severely ill patients with generalized CRPS prompted our interest in a lower dose therapy.

Objective: To report on the efficacy of low dose outpatient ketamine infusion for

Complex regional pain syndrome (CRPS) is characterized by pain that is out of proportion to the injury and is regional in distribution (1). It is primarily caused by peripheral trauma although approximately $10 \%$ occurs from lesions in central pain pathways. A large body of literature now exists both from animal models and clinical experience (2-7) supporting a dynamic change in the physiology and structure of central pain projecting

From: Department of Anesthesiology, Division of Pain Management, Cooper University Hospital, The Robert Wood Johnson Medical School, Camden, NJ; and Department of Neurology, Drexel University College of Medicine, Philadelphia, PA

Address Correspondence:

Michael E. Goldberg, MD

One Cooper Plaza, Camden, NJ 08103

Disclaimer: There was no external funding in prepa-

ration of this manuscript.

Conflict of Interest: None

Acknowledgement:

Manuscript received on $11 / 13 / 2004$

Revision submitted on $2 / 26 / 2005$

Accepted for publication on 2/28/2005 the treatment of CRPS diagnosed by International Association for the Study of Pain (IASP) criteria in patients who have failed conservative treatment.

Design: Open label, prospective, pain journal evaluation of a 10-day infusion of intravenous ketamine in the CRPS patient.

Methods: Patients diagnosed with CRPS by a single neurologist were assigned to receive a 10-day outpatient infusion of ketamine supervised by an Anesthesiologist/ Pain Management Specialist. The infusion was administered in a short procedure unit after each patient had been instructed on how to complete a pain questionnaire. Monitoring consisted of continuous ECG, pulse oximetry, and non-invasive blood pressure every 15 minutes. Patients made journal entries each day prior to the infusion of $40-80 \mathrm{mg}$ of ketamine. The subjects were also asked to rate their pain intensity using a verbal ana- log pain scale of o-10 and the affective component using a verbal scale of $0-4$.

Results: There was a significant reduction in pain intensity from initiation of infusion (Day 1) to the $10^{\text {th }}$ day, with a significant reduction in the percentage of patients experiencing pain by Day 10 as well as a reduction in the level of their "worst" pain. The nadirs of pain were lower by Day 10 with a significant reduction in the incidence of "punishing pain." Moreover, there was a significant improvement in the ability to initiate movement by the $10^{\text {th }}$ day.

Conclusion: A four-hour ketamine infusion escalated from 40-80 mg over a 10-day period can result in a significant reduction of pain with increased mobility and a tendency to decreased autonomic dysregulation.

Keywords: Complex regional pain syndrome (CRPS), ketamine, neuropathic pain

neurons mediated through the N-methyl$\mathrm{D}$-aspartate (NMDA) receptor. The clinical elements include autonomic dysregulation, spontaneous pain, evoked pain and movement disorder, and in severe cases, trophic changes. The incidence has not been determined although it occurs more frequently in females (2).

Present evidence suggests that a persistent nociceptive barrage maintains a state of central sensitization in central pain projecting neurons $(3,4)$. The consequences of central and peripheral sensitization are a lower threshold to fire $\mathrm{C}$ and A delta nociceptors, a spread of cutaneous receptive fields of central projecting neurons, a change in spinal cord and cortical pain maps, and spontaneous pain (5). There are clear changes in the central, autonomic, and motor systems that evolve concomitantly with changes in pain pathways in CRPS (1). Central in this process is the NMDA receptor. The release of the magnesium block at the NMDA receptor with consequent influx of calcium and consequent initiation of intercellular cascades, appears to be a critical factor in initiation of central sensitization $(6,7)$. Experimental and clinical literature supports the effectiveness of ketamine in blocking central sensitization by its effects on the NMDA receptor (8). Ketamine is a drug that is rapidly distributed into the brain and other highly perfused tissues, with about $10 \%$ of the drug bound to plasma. The bioavailability of ketamine is dependent on the route of administration, being as high as $93 \%$ for an intramuscular dose, $20-50 \%$ for an intranasal dose, and approximately $20 \%$ for an oral dose.

Recent treatment with anesthetic doses of ketamine for severely ill, generalized CRPS patients has shown some efficacy and prompted its use in less severely ill patients by low dose infusion (9). The results of this therapy are reported for 40 patients with moderate to severe longstanding CRPS. 
Table 1. Patient treatments prior to ketamine protocol

\begin{tabular}{|c|c|c|c|c|c|c|c|c|c|c|c|c|c|c|c|c|c|c|}
\hline \multirow{2}{*}{$\begin{array}{l}\text { Proportion } \\
\text { of Patients }\end{array}$} & \multicolumn{2}{|c|}{$\begin{array}{l}\text { Physio- } \\
\text { Therapy }\end{array}$} & \multicolumn{2}{|c|}{ NSAID } & \multicolumn{2}{|c|}{\begin{tabular}{|c|} 
Anti- \\
Depressants \\
\end{tabular}} & \multicolumn{2}{|c|}{\begin{tabular}{|c|} 
Anti- \\
Convulsants
\end{tabular}} & \multicolumn{2}{|c|}{ Spasmolytics } & \multicolumn{2}{|c|}{\begin{tabular}{|c|}
$\begin{array}{c}\text { Sodium Channel } \\
\text { Blocker }\end{array}$ \\
\end{tabular}} & \multicolumn{2}{|c|}{ Opioids } & \multicolumn{2}{|c|}{$\begin{array}{c}\text { Sympathetic } \\
\text { Block }\end{array}$} & \multicolumn{2}{|c|}{$\begin{array}{l}\text { Lidocaine } \\
\text { Infusion }\end{array}$} \\
\hline & $\begin{array}{c}\mathrm{B} \\
(37) \\
\end{array}$ & $\begin{array}{c}\mathrm{A} \\
(37)\end{array}$ & \begin{tabular}{|c|}
$\mathrm{B}$ \\
$(37)$ \\
\end{tabular} & $\begin{array}{c}A \\
(37)\end{array}$ & \begin{tabular}{|c|}
$\mathrm{B}$ \\
$(37)$ \\
\end{tabular} & $\begin{array}{c}\mathrm{A} \\
(37) \\
\end{array}$ & \begin{tabular}{|c|} 
B \\
$(37)$ \\
\end{tabular} & $\begin{array}{c}\mathrm{A} \\
(37)\end{array}$ & \begin{tabular}{|c|} 
B \\
$(37)$ \\
\end{tabular} & $\begin{array}{c}\text { A } \\
(37)\end{array}$ & $\begin{array}{c}\mathrm{B} \\
(34) \\
\end{array}$ & $\begin{array}{c}\mathrm{A} \\
(34)\end{array}$ & $\begin{array}{c}\mathrm{B} \\
(36) \\
\end{array}$ & $\begin{array}{c}A \\
(36)\end{array}$ & \begin{tabular}{|c|} 
B \\
$(31)$ \\
\end{tabular} & $\begin{array}{c}\mathrm{A} \\
(31) \\
\end{array}$ & $\begin{array}{c}\mathrm{B} \\
(30) \\
\end{array}$ & $\begin{array}{c}\text { A } \\
(30) \\
\end{array}$ \\
\hline$<10 \%$ & $\begin{array}{l}3 \% \\
(1)\end{array}$ & $0 \%$ & $\begin{array}{l}8 \% \\
(3)\end{array}$ & $\begin{array}{l}3 \% \\
(1)\end{array}$ & $0 \%$ & $\begin{array}{l}8 \% \\
(3)\end{array}$ & $\begin{array}{l}3 \% \\
(1)\end{array}$ & $0 \%$ & $0 \%$ & $0 \%$ & $\begin{array}{l}9 \% \\
(3)\end{array}$ & $\begin{array}{l}6 \% \\
(2)\end{array}$ & $0 \%$ & $\begin{array}{l}3 \% \\
(1)\end{array}$ & $\begin{array}{l}3 \% \\
(1)\end{array}$ & $0 \%$ & $0 \%$ & $0 \%$ \\
\hline $10-30 \%$ & $\begin{array}{l}43 \% \\
(16)\end{array}$ & $\begin{array}{l}97 \% \\
(36)\end{array}$ & $\begin{array}{c}13 \% \\
(5)\end{array}$ & $\begin{array}{l}97 \% \\
(36)\end{array}$ & $\begin{array}{c}16 \% \\
(6)\end{array}$ & $\begin{array}{l}79 \% \\
(29)\end{array}$ & $\begin{array}{c}24 \% \\
(9)\end{array}$ & $\begin{array}{l}83 \% \\
(31)\end{array}$ & $0 \%$ & $\begin{array}{l}35 \% \\
(13)\end{array}$ & $\begin{array}{l}38 \% \\
(13)\end{array}$ & $\begin{array}{l}88 \% \\
(30)\end{array}$ & $\begin{array}{l}3 \% \\
(1)\end{array}$ & $\begin{array}{l}64 \% \\
(23)\end{array}$ & $\begin{array}{c}13 \% \\
(4)\end{array}$ & $\begin{array}{l}97 \% \\
(30)\end{array}$ & $\begin{array}{c}27 \% \\
(8)\end{array}$ & $\begin{array}{l}97 \% \\
(29)\end{array}$ \\
\hline $30-50 \%$ & $\begin{array}{l}46 \% \\
(17)\end{array}$ & $0 \%$ & $\begin{array}{l}57 \% \\
(21)\end{array}$ & $0 \%$ & $\begin{array}{l}81 \% \\
(30)\end{array}$ & $\begin{array}{l}8 \% \\
(3)\end{array}$ & $\begin{array}{l}59 \% \\
(22)\end{array}$ & $\begin{array}{l}3 \% \\
(1)\end{array}$ & $\begin{array}{l}76 \% \\
(28)\end{array}$ & $\begin{array}{l}43 \% \\
(16)\end{array}$ & $\begin{array}{l}41 \% \\
(14)\end{array}$ & $0 \%$ & $\begin{array}{l}78 \% \\
(28)\end{array}$ & $\begin{array}{l}8 \% \\
(3)\end{array}$ & $\begin{array}{l}61 \% \\
(19)\end{array}$ & $0 \%$ & $\begin{array}{l}57 \% \\
(17)\end{array}$ & $0 \%$ \\
\hline$z=50 \%$ & $\begin{array}{l}8 \% \\
(3)\end{array}$ & $\begin{array}{l}3 \% \\
(1)\end{array}$ & $\begin{array}{c}22 \% \\
(8)\end{array}$ & $0 \%$ & $\begin{array}{l}3 \% \\
(1)\end{array}$ & $\begin{array}{l}5 \% \\
(2)\end{array}$ & $\begin{array}{c}14 \% \\
(5)\end{array}$ & $\begin{array}{c}14 \% \\
(5)\end{array}$ & $\begin{array}{c}24 \% \\
(9)\end{array}$ & $\begin{array}{c}22 \% \\
(8)\end{array}$ & $\begin{array}{c}12 \% \\
(4)\end{array}$ & $\begin{array}{l}6 \% \\
(2)\end{array}$ & $\begin{array}{c}19 \% \\
(7)\end{array}$ & $\begin{array}{c}25 \% \\
(9)\end{array}$ & $\begin{array}{c}23 \% \\
(7)\end{array}$ & $\begin{array}{l}3 \% \\
(1)\end{array}$ & $\begin{array}{c}16 \% \\
(5)\end{array}$ & $\begin{array}{l}3 \% \\
(1)\end{array}$ \\
\hline
\end{tabular}

Patients reported initial and long-term quality of analgesia for their various therapies prior to entry into the intravenous Ketamine protocol.

B -Before indicates pain relief achieved for up to 8 weeks while on any one of the above therapies

A: After indicates chronic pain relief $>8$ weeks in duration. Three patients' clinical records could not be located which explains $\mathrm{n}=37$.

\section{Methods}

After approval from the local Institutional Review Board, 40 American Society of Anesthesiologists, Physical Status Classification I or II patients with a primary diagnosis of CRPS I or II gave written informed consent to participate in this prospective study.

The patients had a history of longstanding or rapidly spreading CRPS, refractory to conventional therapy which included: a) Physical therapy; b) drug combinations of NSAIDS, tricyclic antidepressants, anticonvulsants, and opioids; c) sympatholysis either by intermittent superior cervical or paravertebral block, or five days intrapleural or epidural block. Four patients had failed a therapeutic trial of dorsal column stimulation. The patients referred for therapy were diagnosed to have persistent and/or progressive severe disease, and no known contraindications to ketamine, clonidine, or midazolam. Prior to entering the ketamine protocol, these patients had been treated for a period of three months to three years.

The ketamine infusion was administered on an outpatient basis under the supervision of an Anesthesiologist/Pain Specialist. The same neurologist (RJS) made the diagnosis of CRPS based on the International Association for the Study of Pain (IASP) criteria. Patients were maintained on their usual medications/treatments and those were not altered during the infusion period (Table 1). The baseline physical exam also included a general as- sessment of the patient's ability to initiate movement of the effected extremity using a 10-point scale.

Prior to ketamine infusion, subjects were admitted to a short procedure unit and instructed on proper completion of a pain questionnaire. They were monitored with continuous ECG, pulse oximetry, and non-invasive blood pressure every 15 minutes. Forty- $80 \mathrm{mg}$ of ketamine was mixed in $500 \mathrm{cc}$ of a normal saline solution. All of the patients were started on a $40 \mathrm{mg}$ infusion lasting four hours, and the infusion was increased over a ten-day period to a maximum of $80 \mathrm{mg}$. Each patient also received clonidine $0.1 \mathrm{mg}$ orally prior to the infusion to prevent a hypertensive response and possible muscle pain, as well as midazolam (2-4 mg) to relieve anxiety. Throughout the treatment period, patients were monitored for side effects including: hypertension, tachycardia, dysphoria, hallucinations, dreams, and headaches. The infusion was spread over a twoweek period excluding weekends. Patient journal entries were made each day prior to infusion. The subjects were asked to rate the intensity of their pain using a verbal analog pain scale of $0-10(0=$ no pain, $10=$ worst pain possible) and the affective component of their pain using a verbal scale of $0-4(0=$ none, $1=$ mild, $2=$ moderate, 3 = severe).

Pain data were analyzed using the Kruskall-Wallis test with $\mathrm{p}<0.05$ considered statistically significant. Data are presented as mean \pm standard deviation.

\section{RESULTS}

Thirty-six female and four male patients participated in the study. Mean demographic data for age, weight, and height were $42 \pm 10$ years, $156 \pm 45$ lbs., and $65 \pm$ 3.5 inches respectively. Compared to baseline there were significant $(\mathrm{p}=0.001)$ reductions in pain intensity $(7.54 \pm 1.93$ vs. $5.44 \pm 2.87$ ) (Fig. 1) and in percentage of overall pain relief by the $10^{\text {th }}$ day $(43.61 \pm$ 27.79) (Fig. 2). Analysis of each patient's journal for levels of "worst daily pain" experienced revealed a significant reduction $(\mathrm{p}<0.001)$ in this measure by the $10^{\text {th }}$ day of infusion $(8.77 \pm 1.33$ vs. $6.63 \pm 2.72)$ (Fig. 1).

Compared to the first day of treatment, patients also had a lower "least daily pain" score $(\mathrm{p}=0.006)$ by the $10^{\text {th }}$ infusion day $(5.91 \pm 2.19$ vs. $4.24 \pm 2.75)$ (Fig. $1)$. In this population where pain was also described as burning, aching, and punishing, we found that a significant reduction $(p=0.007)$ in the incidence of "punishing pain" was achieved by the $10^{\text {th }}$ day of infusion $(1.61 \pm 1.22$ to $0.82 \pm 1.13)$ (Fig. 3).

In addition, patients were asked to summarize their pain level over the previous 24 hours as another measure over time of treatment efficacy. By the $10^{\text {th }}$ day of infusion this pain measure had also been reduced significantly $(7.88 \pm 2.02$ vs. $5.5 \pm 2.75)$ (Fig. 1) $(\mathrm{p}<0.001)$.

Patients' ability to initiate movement showed significant improvement $(\mathrm{p}=0.012)$ by the $10^{\text {th }}$ day of infusion (6.4 \pm 2.6 vs. $4.4 \pm 3.2$ ) (Fig. 4 ). A trend to- 


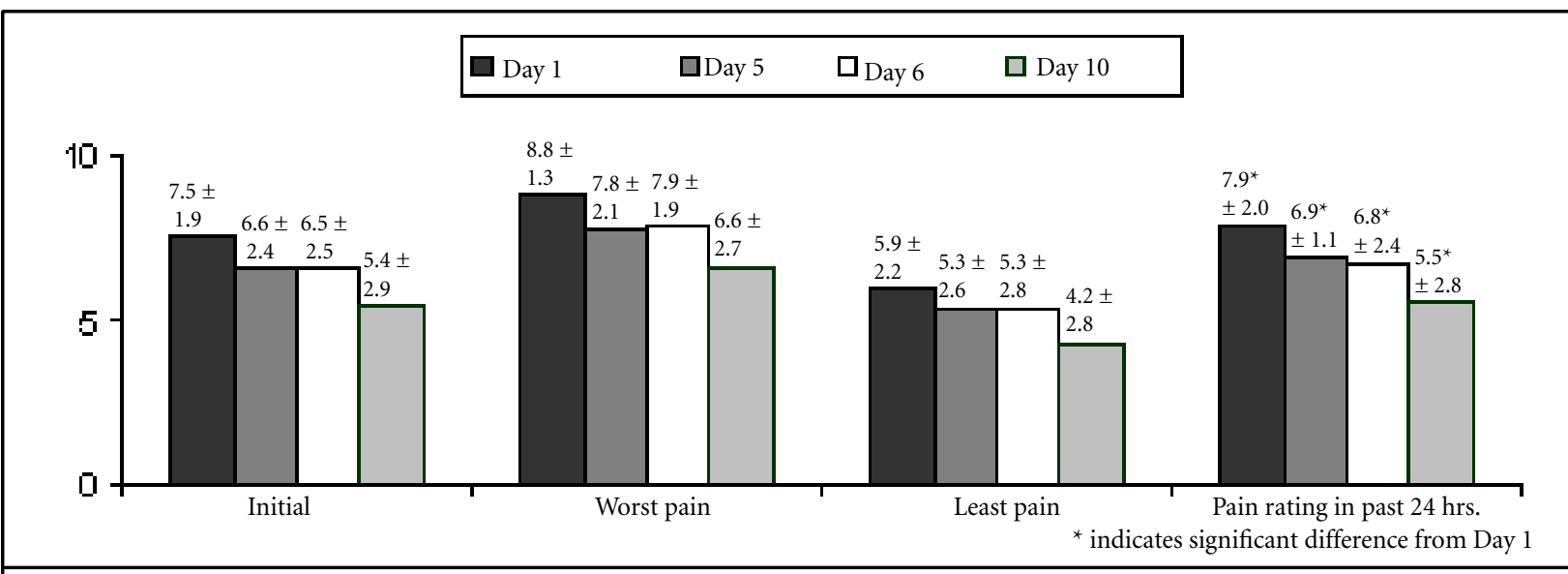

Fig 1. Pain intensity (mean) at 1. initial, 2. worst pain, 3. least pain, and 4. pain rating in past 24 hrs.

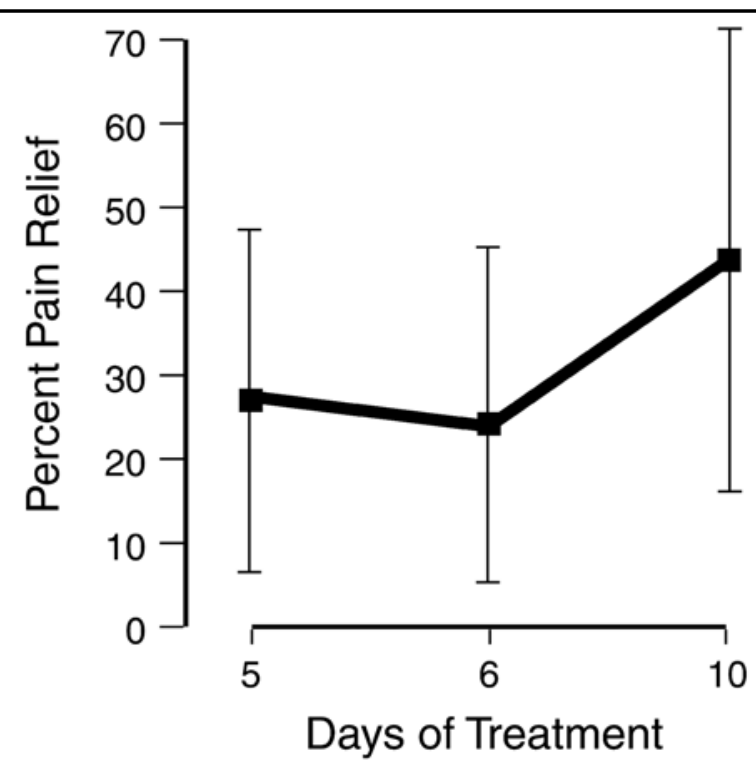

Fig. 2. Percent pain relief from days 1 through 10 (mean $\pm S D)$

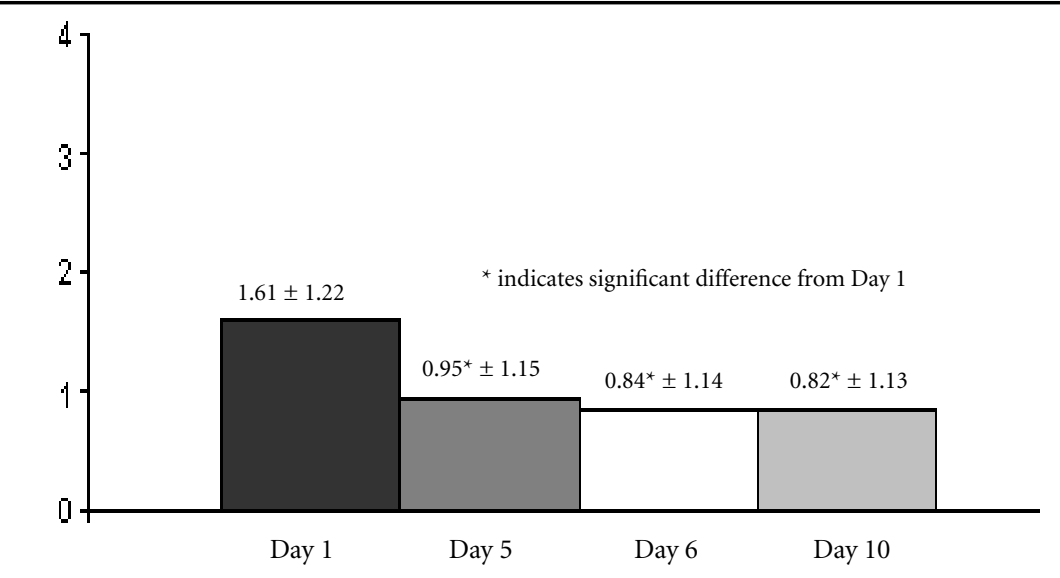

Fig 3. Mean pain intensity punishing type pain intensity wards a reduction in skin color changes was noted by the $10^{\text {th }}$ day of infusion although this observation did not reach statistical significance. Overall, side effects were minimal with $4 / 40$ and $5 / 40$ patients reporting headaches and restlessness respectively with infusion. There were no episodes of desaturation $\left(\mathrm{SpO}_{2}<93 \%\right)$ and $3 / 40$ patients experienced a $20 \%$ increase over their baseline heart rate during the infusion of ketamine. None of these side effects required intervention. No patient reported hallucinations or nightmares over the duration of exposure to ketamine.

All of the patients expressed positive feelings about the treatment, the quality of their pain relief, and confirmed that they would have no objection to repeating this mode of therapy if necessary. Finally, all of the changes recorded in the variables measured appeared to be progressive over the days of infusion (Figs. 1-4).

\section{DisCUSSION}

Complex regional pain syndrome is often described by patients as burning, throbbing, or aching pain, as well as mechano- and thermal allodynia (1). The syndrome is often debilitating and can result in complete disability. Multiple treatment modalities have been attempted including physical therapy, psychotherapy, behavior modification, surgery, interventional pain therapies, and medications $(16,17)$. All were reported to have some degree of success, but with great variability in the quality of the response. In the most severe cases, the interventional treatments are short lived and may not show positive effects.

Multiple studies have suggested that 


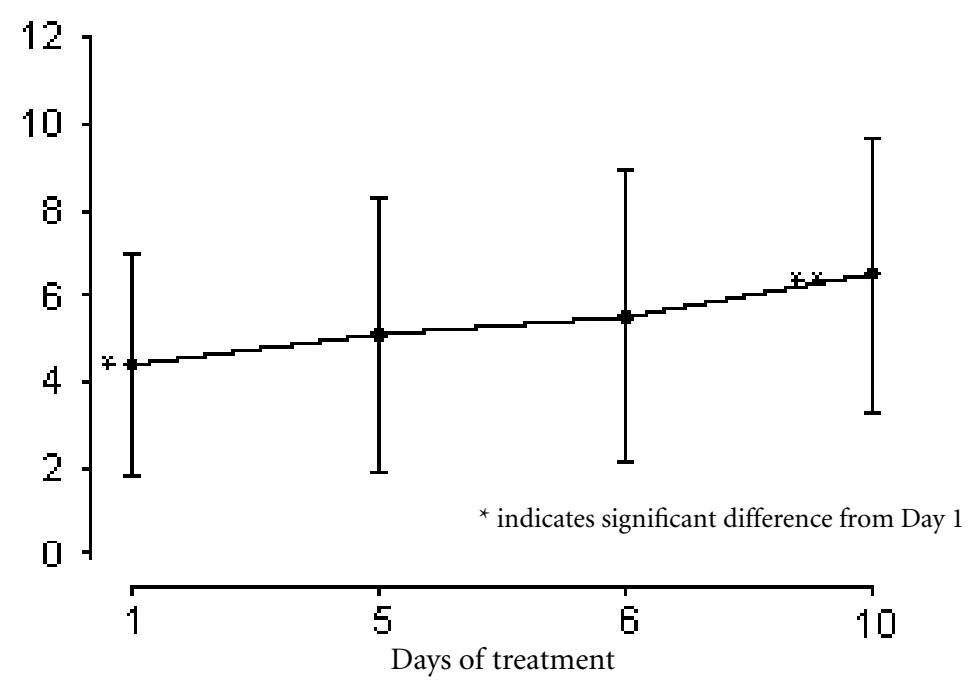

Fig 4. Ability to initiate movement during the 10 days infusion (mean $\pm S D)$

the use of N-methyl-D-aspartate receptor antagonists can reduce the pain response in patients with neuropathic pain (1821). These receptors are phosphorylated and their channel properties are altered, thereby changing the physiology of central pain projecting neurons $(22,23)$.

The goal of our treatment modality was to expand on the technique previously described by Kiefer et al (15). In that study, patients with severe CRPS who had been resistant to conservative therapies successfully underwent high dose (coma inducing) ketamine therapy in an ICU setting (15). This procedure may have significant risks and other difficulties resulting from five days of immobilization, risk of nosocomial infection, need for invasive monitoring, parenteral nutrition, endotracheal intubation, and mechanical ventilation. Therefore, our rationale for the treatment of these less severely affected patients was to use a technique of low dose ketamine administration, and a longer infusion. The maximum dose used in this study $(20 \mathrm{mg} / \mathrm{hr}$ ) was well below the reported doses associated with psychomimetic effects $(5,24)$.

The results indicate that the use of an escalated infusion, from $40 \mathrm{mg}$ over four hours to $80 \mathrm{mg}$ over four hours/day for 10 days, can result in significant reduction of pain with increased mobility and a tendency to decreased autonomic dysregulation. Our patients reported a significant increase in pain relief and a decrease in their worst episodes of pain that we believe to be clinically significant. Furthermore, patients reported that the pain, when reduced, was much more tolerable over a given 24 -hour period. The improvement was noted to be progressive over the infusion period and suggests that continued treatment (longer than 10 days) might produce a more significant response. At the time of publication of this manuscript we report that four patients $(10 \%)$ had a return of "worst" and "punishing" pain to pre-infusion levels by two weeks post treatment. Twenty-five patients $(62 \%)$ had at least a $70 \%$ reduction of "worst" and "punishing" pain for six weeks and were back to baseline pain levels by nine weeks post treatment. Eight patients $(20 \%)$ had a $>70 \%$ reduction in those same pain measures for 11-12 weeks. Three patients remain CRPS free at 15 months following treatment.

\section{Conclusion}

The results of this study demonstrated clinically significant benefits of the technique in this specific patient population. Although pain data showed some variability, the results are encouraging and point to the need for additional studies (i.e., oral medication, longer therapy, more specific therapies) with specific NMDA receptor antagonists in this population. Further studies with specific NMDA receptor antagonists would be beneficial in this population.
ACKNOWLEDGMENTS

The authors wish to thank the editors of Pain Physician for peer review and constructive criticism, which ultimately improved the quality and understanding of the manuscript.

\section{Author Affiliation:}

Michael E. Goldberg, MD

Chief, Department of Anesthesiology

Professor of Anesthesiology

UMDNJ - Robert Wood Johnson

Medical School at Camden

Cooper University Hospital

One Cooper Plaza

Camden, NJ 08103

E-mail Goldberg-

mike@cooperhealth.edu

Richard Domsky, MD

Co-Director, Division of Pain

Management, Cooper University

Hospital, One Cooper Plaza

Camden, NJ 08103

Denise Scaringe, MD

Attending Anesthesiologist

Cooper University Hospital

One Cooper Plaza

Camden, NJ 08103

Robert Hirsh, MD

Co-Director, Division of Pain

Management, Cooper University

Hospital, One Cooper Plaza

Camden, NJ 08103

Jessie Dotson, MSN

Advance Practice Nurse, Division of

Pain Management, Cooper University

Hospital, One Cooper Plaza

Camden, NJ 08103

Imran Sharaf, MD

Resident in Anesthesiology

Cooper University Hospital

One Cooper Plaza

Camden, NJ 08103

Marc C. Torjman, Ph.D.

Director of the Division of Research

Department of Anesthesiology

Cooper University Hospital

Education and Research Building,

Suite 394, 401 Haddon Avenue,

Camden, NJ 08103

Robert J. Schwartzman, MD

Professor and Chairman, Department of Neurology

Drexel University College of Medicine 245 N. $15^{\text {th }}$ Street Mail Stop 423

Philadelphia, PA 19102 


\section{References}

1. Janig W, Baron R. Complex regional pain syndrome: Mystery explained? Lancet Neurol 2003; 2:687-697.

2. Bell RF. Low-dose subcutaneous ketamine infusion and morphine tolerance. Pain 1999; 83:101-103.

3. Clark JL, Kalan GE. Effective treatment of severe cancer pain of the head using lowdose ketamine in an opioid-tolerant patient. J Pain Sympt Manag 1995; 10:310314.

4. Eide PK, Jorum E, Stubhaug A, Bremnes J, Breivik H. Relief of post-herpetic neuralgia with the N-methyl-D-aspartic acid receptor antagonist ketamine: A double-blind, cross-over comparison with morphine and placebo. Pain 1994; 58:347-354.

5. Harbut RE, Correll GE. Successful treatment of a nine-year case of complex regional pain syndrome type-i (reflex sympathetic dystrophy) with intravenous ketamine-infusion therapy in a warfarin-anticoagulated adult female patient. Am Acad Pain Med 2002; 3:147-155.

6. Correll GE, Maleki JM, Gracely EJ, Muir JJ, Harbut RE. Subanesthetic ketamine infusion therapy: A retrospective analysis of a novel therapeutic approach to complex regional pain syndrome. Pain Med 2004; 5 : 263-275.

7. Kvarnstrom A, Larlsten $\mathrm{R}$, Quiding $\mathrm{H}$, Emanuelsson BM, Gordh T. The effectiveness of intravenous ketamine and lidocaine on peripheral neuropathic pain. Acta Anaesthesiol Scand 2003; 47:868-877.

8. Baron R, Fields HL, Janig W, Kitt C, Levine JL. National Institute of Health Workshop: Reflex sympathetic dystrophy/complex re- gional pain syndromes: State of the sciences. Anesth Analg 2002; 95:1812-1816.

9. Schwartzman RJ, Popescu A. Reflex sympathetic dystrophy. Curr Rheumatol Rep 2002; 4:165-169.

10. Sheng M, Kim MJ. Postsynaptic signaling and plasticity mechanisms. Science 2002; 298: 776-780.

11. Ji RR, Wolf CJ. Neuronal plasticity and signal transduction in nociceptive neurons: implications for the initiation and maintenance of pathologic pain. Neurobiol Dis 2001; 8:1-10.

12. Caroll RC, Zukin SR. NMDA-receptor trafficking and targeting: implications for synaptic transmission and plasticity. Trends Neurosci 2002; 25:571-577.

13. Choquet D, Triller A. The role of receptor diffusion in the organization of the post synaptic membrane. Nat Rev Neurosci 2003; 4:251-265.

14. Hirota K, Lambert DG. Ketamine: Its mechanism of action and unusual clinical uses. Br J Anaesth 1996; 77:441-444.

15. Kiefer RT, Rohr P, Unertl K, Altemeyer KH, Grothusen J, Schwartzman RJ. Recovery from intractable complex regional pain syndrome type I (RSD) under high dose intravenous ketamine-midazolam sedation. Neurology 2002; 58A:475.

16. Smith DJ, Bouchal RH, DeSanctis CA, Monroe PJ, Amedro JB, Pliotti JM, Crisp T. Properties of the interaction between ketamine and opiate binding sites in vivo and in vitro. Neuropharmacol 1987; 26:1253-126o.

17. Schwartzman RJ, McLellan TL. Reflex sympathetic dystrophy. Arch Neurol 1987; 44: 555-561.

18. Kochs E, Scharein E, Molenberg O, Bromm
B, Scutte J. Analgesic efficacy of low dose ketamine. Anesthesiology 1996; 85:304314 .

19. Oga K, Kojima T, Matsuura M, Nagashima M, Kato J, Saeki S, Ogawa S. Effects of lowdose ketamine on neuropathic pain. An electroencephalogram-electrooculogram/ behavioral study. Psych Clin Neuro 2002; 56:355-363.

20. Klepstad P, Borchgrevink P, Hval B, Flaat $\mathrm{S}$, Kaasa S. Long-term treatment with ketamine in a 12-year-old girl with severe neuropathic pain caused by a cervical spinal tumor. J Pediatr Hematol Oncol 2001; 23: 616-619.

21. Nadeson R, Tucker A, Bajunaki E, Goodchild CS. Potentiation by ketamine of fentanyl antinociception I. An experimental study in rats showing that ketamine administered by non-spinal routes targets spinal cord antinociceptive system. $\mathrm{Br} J$ Anaesth 2002; 88:685-691.

22. Schwartzman RJ. The autonomic nervous system and pain. In Appenzella $O$ (ed) Handbook of Clinical Neurology, Elsevier Science, New York, 2001, pp 75:309-347.

23. Hall R, Murdoch J. Brain protection: physiologic considerations. Part II: The pharmacology of brain protection. Can J Anaesth 1990; 37:762-777.

24. Schmid RL, Sandler AN, Katz J. Use and efficacy of low-dose ketamine in the management of acute post-operative pain: a review of current techniques and outcomes. Pain 1999; 82:111-125. 